\title{
Old war, new battleground: Deconstructing the potency of social media for community engagement in Nigeria's human rights advocacy efforts
}

\author{
Joel Chinedum Ugwuoke \\ University of Nigeria, Nigeria \\ Joshua Aghogho Erubami ${ }^{1}$ \\ Delta State University, Nigeria
}

To cite this article: Ugwuoke, J. C., \& Erubami, J. A. (2021). Old war, new battleground: Deconstructing the potency of social media for community engagement in Nigeria's human rights advocacy efforts. World of Media. Journal of Russian Media and Journalism Studies 2. DOI: 10.30547/worldofmedia.2.2021.3

\begin{abstract}
Although the need to guarantee human rights has been long acknowledged, efforts towards their full realization seem limited to the sole reliance on the conventional top-down approach to development. However, current development discourse emphasizes the centrality of people's involvement in social development, such as human rights promotion, and the social media seem to hold considerable prospects in the actualization of this goal. Using a survey of 1,000 respondents drawn from states across Nigeria, this study investigates how new media technologies, such as social media, are shifting focus from the sole reliance on the mainstream media and influencing public involvement in human rights promotion in Nigeria. Findings showed that the social media have engendered community-wide engagements of people in efforts aimed at reducing cases of human rights violation in Nigeria, as people do not only get exposed to human rights issues on the social media, but also participate in their discussion and promotion. Overall, using the social media for human rights advocacy was significantly associated with respondents' gender $\left(.528^{* *}\right)$, education $\left(.674^{* *}\right)$, perception $\left(.753^{* *}\right)$, and social media exposure $\left(.421^{* * *}\right)$. Hence, there is the need for stakeholders to leverage the potentials of the social media in the promotion of people's fundamental rights.
\end{abstract}

\footnotetext{
${ }^{1}$ Corresponding author:

Joshua Aghogho Erubami, Department of Mass Communication, Delta State University, P.M.B. 1, Abraka, Delta State, Nigeria.

Email: erubami26@gmail.com
} 


\section{Keywords}

Civil liberty, development advocacy, media perception, social change, technoactivism, Web 2.0.

\section{Introduction}

Human rights constitute some of the key elements of true development, and since the dawn of history, the quest to guarantee man's inalienable rights has remained a major preoccupation of governments, groups, and individuals around the world. This singular desire has reflected in several international and regional treaties, such as the Universal Declaration of Human Rights in 1948 and the African Charter on Human and People's Rights in 1981. Generally, a good development effort should aim at liberating the beneficiaries from the social drawbacks of wants, ignorance, economic exploitation, and social injustice (Uwakwe, 2012). Such effort should also stimulate the process of economic and social advancements that enable people to realize their innate potentials as agents of change, build self-confidence in their ability to take part in worthwhile ventures, and lead lives of dignity and self-fulfillment in the pursuit of individual and community advancement (Soola, 2003). It is partly on the stretch of this realization that the 2030 agenda for sustainable development identifies the protection of human rights as prerequisites for national development (United Nations, 2019).

The concept of human rights has attracted numerous theorizations. In its most basic form however, human rights refer to the inalienable freedoms and benefits that are enjoyed by individuals in the society they live in. These rights comprise all the civil liberties that every citizen of a country ought to enjoy without any form of deprivation except for reasonably justified grounds that are pre-established by the constitution of such a country (Asemah et al., 2013). Human rights are natural rights and considered as basic preconditions for every individual to live a meaningful life as a member of the society; hence, it becomes unreasonable to deprive anyone of such rights without causing a grave affront to justice. These rights broadly include the right to life, dignity of human beings, personal liberty, and freedom from torture and discrimination based on gender, religion, ethnic or political affiliation among others (Pate, 2011).

As a country, Nigeria is faced with diverse socio-political challenges despite its immense human resources and economic potentials (Akoja, 2016). About $40.1 \%$ ( 82.9 million) of its population are considered poor by national standards, and the country grapples with access to basic indices of physical development, including good roads, portable water, and stable electricity supply (Nigeria. National Bureau of Statistics [NBS], 2020). Nigeria's development imbroglios 
are also manifest in its social challenges as basic human rights claims, such as social justice, human dignity, privacy, equality and protection against violence and forced labour, are seemingly not easy to assert (Nzarga, 2014). Several reports indicate that on a nearly daily basis, women are violently raped; young girls are subjected to genital mutilation and early marriage; boys risk being subjected to forced labour (Amnesty International, 2019). In 2015, about 6 out of every 10 Nigerian children experienced varied degrees of violence, while $10 \%$ of boys and 1 in 4 girls were reported to have been sexually abused. Similarly, more than 23 million girls and women have suffered forced or early marriage and about 19.9 million others have undergone female genital mutilation despite global efforts to abolish the practice (UNICEF, 2015).

Although there are some noticeable efforts by governments and other stakeholders to quell the spread of human rights violation in Nigeria, scholars advocate significant paradigm changes in the approach to the challenge viz: the extent of public involvement and the platform of engagement. On the one hand, scholars assert that, like other social development efforts, the success of human rights advocacy initiatives demands an appreciable level of communitywide participation and involvement of all concerned stakeholders, including the media and the public (Uwakwe, 2012).

On the other hand, they contend that despite the recognition of the mainstream media as the major crusaders of national development efforts (Choudhory, 2011; Moemeka, 2012), the peculiar potentials inherent in the social media should be effectively deployed to raise public awareness and trigger wide scale movements on human rights issues (Mwilima \& Matali, 2018; Rahamn, 2016). Such arguments are premised on the fact that the social media promote two-way communication engagements that tend to enhance people's capacity to challenge human rights abuses and participate in social development efforts (Fayoyin, 2011). With respect to human rights issues, the social media help to shatter the psychological hurdle of fear and help users to realize that they are not alone and that there are many other people experiencing as much brutality, hardship and injustice as they are experiencing (Mwilima \& Matali, 2018). Consequently, current emphasis is on how the social media can be used to create a new public sphere that enables a large number of people to exchange views for the promotion and protection of human rights (Zanzoun, 2017).

This study reclines on investigating the various ways in which social media users participate in human rights development efforts in Nigeria, and how they perceive digitally mediated human rights advocacy issues posted on the social media. In the pursuit of these objectives, the study was guided by the following 
research questions: (i) To what extent are social media users in Nigeria exposed to human rights advocacy messages posted online? (ii) How do Nigerians participate in human rights advocacy efforts using the social media? (iii) What is the perception of Nigerians towards the effectiveness of the social media as tools for human rights advocacy? (iv) What are the factors associated with the deployment of the social media for human rights advocacy efforts in Nigeria?

\section{Literature review}

The concept of development has continued to assume dynamic dimensions, moving away from its traditional model of physical or tangible infrastructural growth to social issues which, though intangible, are crucial to societal wellbeing. Human rights constitute one of the social issues that define the overall level of development of any society (United Nations, 2019). Modern development discourse places people at the centre of developmental efforts in order for the beneficiaries of development projects to build their capacities and realize their individual potentials (Nicholson et al., 2016; Soola, 2003). This, therefore, underscores the need for community engagement in development initiatives.

Community engagement gives the ordinary people the much-needed opportunities to play active roles in the definition of peculiar development challenges, identification of solutions and development of priorities for action and resources (Bassler et al., 2008). Its basic goals are to increase citizens' knowledge on burning issues, and to encourage the application of such knowledge in the improvement of community wellbeing and creation of regular and on-going opportunities (Bassler et al., 2008).

The mass media can be used to support and realize these goals by informing people about on-going development projects, instructing them on the roles to play, and stimulating general participation in such projects (Asemah et al., 2013). For example, the mass media can be deployed to shape people's opinion and behavior towards human rights issues, disseminate information on such issues, mobilize support groups and strengthen popular participation in the activities of civil society organizations (Okeke, 2014). In this regard, the mass media generally provide an effectual network for informing and educating people on issues related to human rights and make human rights violators realize their wrongful acts. Specifically, the roles of the mass media in human rights protection include uncovering cases of human rights violations, exposing perpetrators of human rights abuses for moral condemnation and legal action, and educating people on appropriate channels for seeking redress when their rights are violated (Asemah et al., 2013). 
The social media is a broad term for the new variant of online technologies that enable users to engage in the exchange of information and creation of communication values through the virtual space. These digital platforms are offshoots of the Web 2.0 technology which relies on computer-mediated tools to promote online community building, creation of social values and facilitation of discussions among spatially dispersed people (Erubami, 2020). A major strength of the social media is their ability to enhance a free and timely flow of information among users, thereby promoting human liberty and extending the frontiers of man's inalienable right to freedom of speech and expression.

Observably, modern technological advances have influenced the manner and extent of social activism around the world. Since the wake of the popular Arab uprising, there seems to be a significant rise in techno-optimism about the potentials of digital tools, such as the social media, to enhance human rights advocacy efforts (McPherson, 2017). Scholars contend that the social media hold the capacity to boost human rights advocacy by disrupting the conventional pathway to visibility, ensuring direct citizens-policymakers interaction, and promoting equality of visibility among users (Auger, 2013; Nah \& Saxton, 2013; Thrall et al., 2014).

In recent times, the social media are unsettling human rights key practices around the world, especially in the prevention of human rights abuses, investigation of human rights violations, advocacy for redress in cases of violation, and promotion of the broader culture of human rights across different strata of the society (McPherson, 2015). As a result of the high visibility afforded by the social media technology, individuals and civil society organizations across the globe have embraced the platforms to push for the protection of the civil liberties that are accruable to people in the society they live in (McPherson, 2017; Zanzoun, 2017).

In 2010, a horrifying video that documented the summary execution of Tamil prisoners by Sri Lankan soldiers was captured with a mobile phone and circulated on various platforms, including the social media. After series of verifications that confirmed its authenticity, the anonymous video provided evidence of grave violation of the prisoners' right to life by the Sri Lankan army (McPherson, 2015). Similarly, in May 2020, the social media were used to spread video evidence against an illegal act of police brutality and extra-judicial murder of a 46-year-old African American, George Floyd, in Minneapolis. The video shared on the social media captured the last words of the dying George Floyd, 'Please, I can't breathe', as the erring police officer, Derek Chauvin, pinned him to the ground with his knees on Floyd's throat. The video immediately 
incited public outcry and protests against police brutality and systemic racism in American cities as millions of people within and outside the US condemned the police action and demanded immediate prosecution of the officers involved. The video also electrified online campaigns across various social media platforms and sparked off the \#BlackLivesMatter movement coordinated by civil society organizations.

Previous studies indicate that the social media hold considerable prospects for empowering people to become informed and active advocates of human rights by promoting access to and utilization of key services that aid the fulfillment of such rights (Fafoyin, 2011). The Web 2.0 based platforms have the capacity to engender wide public participation in social mobilization and development efforts in ways that previously seemed impossible with other means of communication, such as newspaper, radio, and television (Dunu \& Uzochukwu, 2015). For example, the social media were used to mobilize over 51,000 landless Namibian youths to apply for land, forcing the government to make policy adjustments in favor of young Namibians (Mwilima \& Matali, 2018). Despite these potentials, there seems to be a discrepancy between the perceived effectiveness of the social media as tools for human rights activism and their actual deployment for such purpose. Zanzoun's (2017) study shows that although human rights activists in Morocco acknowledge the significant role of the social media in mobilizing and facilitating linkages between dispersed groups with a view to promoting human rights practices, only two in 10 activists are likely to deploy the technology in the promotion of human rights.

In the past, the mainstream media were solely recognized and used for media engagements in development activities, including human rights advocacy efforts. However, scholars have consistently criticized the sole reliance on the mainstream media for development communication purposes due to their perceived drawbacks of delayed feedback and one-way communication approach (Moemeka, 2012). Besides, the burning need to promote human rights calls for a corollary media arrangement that relies neither on the parochial agenda of its political or corporate masters nor the prejudices or stereotypes promoted by its own industry (Zanzoun, 2017). The social media offer users the opportunity to overcome these challenges through their unique qualities that enable the personalization of contents according to individual user's needs, presentation of timely and relevant contents in multiple formats and context, and participation of diverse groups who develop and contribute contents in meaningful ways (Dunu \& Uzochukwu, 2015; Erubami, 2020). 
With the social media, users can receive diverse information on human rights issues, share, retweet or rebroadcast same with numerous online friends, and independently create new human rights related stories to immediately gain empathy for victims of human rights abuses and stimulate action in their favor. Social media users can also utilize the platforms to design human rights petitions and call for signatories online or instigate a mass action simply by using the hash tag -\#- which is an exceptionally good way of managing online information and attracting global attention (Okeke, 2014).

For instance, in April 2019, a viral video of a university student, whose mobile telephone was destroyed after being unjustly brutalized by a police officer, became a point of national debate after it was posted on the social media. The ensuing public uproar made the Nigeria Police authority to sanction the erring officer and electrified a latent nationwide online social campaign, \#ENDSARS, which called for the immediate disbandment of the country's Special Anti-Robbery Squad (SARS) over its alleged brazen abuse of human rights. Similarly, in October 2020, social media tools, such as Twitter, Facebook and Youtube, were used to coordinate and mobilize young Nigerians for the \#EndSARS protest which is regarded as the most significant civil uprising in Nigeria. Earlier, the hash tag had been used by the 'Bring Back Our Girls' group, $\# B B O G$, to initiate and sustain a social campaign that pushed for the release of over 200 Chibok Community School girls abducted by Boko Haram insurgents in Nigeria's North-East.

\section{Theoretical framework}

The study was anchored on the Media Systems Dependency Theory (MSDT) which seeks to explain the relationship among individuals, the media and the social milieu in which they function. The theory emanated from the works of Sandra Ball-Rokeach and Melvin Defleur who posited that the availability of information resources leads to changes in individuals' cognition, emotion and behavior (Wimmer \& Dominick, 2011). In their article published in 1976, the researchers attempted to explain why the media have distinct cognitive, affective and behavioral effects on different people.

A major assumption of the MSDT is that individuals are goal-oriented and active in their selection and use of media contents such that they may depend on a source or medium for action orientation and interaction orientation to enable them act purposefully and exhibit the desired behavior in the pursuit of their goals. In this case, dependency on a source or medium does not necessarily require its exclusive or daily use; rather, it borders on whether a source or 
medium constitutes an important part of an individual's information mix. Thus, people's use of certain media sources for specialized information tend to index their dependency on that source more than their general and non-specific media exposure does (Riffe et al., 2008).

In consonance with the theory, the current paper assumes that the availability of social media information resources may influence the cognitive, affective and evaluative domains of individual users of the social media and stimulate changes in their level of active engagement in human rights advocacy efforts using the social media. Studies indicate that the social media have become veritable sources of information to many Nigerians and the use of these online platforms constitutes an integral aspect of their daily lives (Oji \& Erubami, 2020). With over 126 million people maintaining online presence in 2019, Nigeria has the highest number of Internet users on the African continent (Internet World Stats, 2020); thus, suggesting some levels of people's dependence on online media platforms for general and/or specialized information. Based on this sort of dependency, the social media may be explored to engender a community wide participation and shape people's perception on human rights issues such that their abuses or violations are immediately observed, censured or commended as the case may be.

\section{Methods}

The study adopted the survey research approach which is suitable for examining many variables, including peoples' opinion, attitude, perception and intention towards a given problem or societal occurrence (Asemah et al., 2017). The population of study comprised all residents of states in the South-East and South-South geopolitical zones of Nigeria. The South-East zone consists of five states and occupies about $41,440 \mathrm{~km}^{2}$, with an estimated population of $21,955,414$ people, while the South-South zone consists of six states and occupies a total land mass of approximately $85,303 \mathrm{~km}^{2}$, with an estimated population of 28,829,288 residents (Agbor \& Ashabua, 2018; NBS, 2018). As a country, Nigeria has a densely populated and heterogeneous socio-cultural outlook, and it is generally divided into two main regional blocs of north and south which are further divided into six geopolitical zones. However, the scope of the current study covered only the Southern region which has the highest Internet and social media penetration rates (Teragon Insight, 2013). Besides, the Southern region of Nigeria also accounts for a significant number of documented cases of human rights violation in the country (Ejifoma, 2016). 
A sample size of 1,000 social media users in Nigeria was drawn for the study following Comrey and Lee's recommendations that a sample of 50 is extremely poor; 100 is poor; 200 is fair; 300 is good; 500 is very good; and 1,000 is excellent (Wimmer \& Dominick, 2011). A multistage sampling technique was used to select the respondents. In the first stage, the stratified sampling technique was used to divide the two geopolitical zones into separate states. The states were Abia, Anambra, Ebonyi, Enugu, and Imo (for South-East) and Akwa-Ibom, Balyesa, Cross River, Delta, Edo and Rivers (for South-South). In the second stage, the simple random sampling technique was used to select two states to represent each zone using a lucky dip. At the end of the selection, Anambra and Enugu (from South-East Nigeria) and Bayelsa and Delta (from South-South Nigeria) were picked. In the third stage, purposive sampling was used to select the capital city of the four states; hence, Awka in Anamabra, Enugu City in Enugu, Yenagoa in Bayelsa and Asaba in Delta were purposively selected. Given the cosmopolitan nature of these areas, it is expected that they will have a significantly higher level of Internet penetration and social media usage than other parts of the state. Besides, these urban areas also tend to be more notorious for documented cases of human rights violation than other parts of the study area. For example, Enugu City features prominently on the charts of human rights abuses, recording the highest number of sexual violations against minors in 2015 (Ejifoma, 2016). The final respondents were selected through purposive sampling, using having at least basic education and active usage of the social media as the main inclusion criteria.

Instrument. A 5-point Likert scale questionnaire was used as the instrument for data collection. The instrument was designed with due consideration to previous studies (Asemah et al., 2013; Mwilima \& Matali, 2018; Okeke, 2014; Zanzoun, 2017). 250 copies of the questionnaire were distributed in each of the study locations. Prior to data collection, a pre-test survey was conducted to determine the reliability of the instrument which yielded acceptable Cronbach's Alpha for the three measures - exposure to human rights advocacy messages (.866), participation in human rights advocacy (.824) and perception of social media effectiveness (.785). The data were collected between August 13, 2020 and September 28, 2020 with the help of four research assistants who were university graduates of mass communication.

\section{Measures}

Exposure to human rights advocacy. This variable was measured with a 5-point Likert scale with possible responses ranging from Strongly disagree 
(1) to Strongly agree (5). Respondents were required to rate their extent of agreement or disagreement with the following questions: (1) I do come across videos/written stories concerning human rights violation posted on the social media; (2) I have received requests on the social media urging me to sign online petitions against human rights violation in Nigeria; (3) I am a member of human rights advocacy group/chat room/page on the social media; (4) I have acquired much knowledge on human rights issues through the social media.

Participation in human rights advocacy. To measure this variable, the study participants were required to value their responses on a 5-point Likert scale, ranging from Strongly disagree (1) to Strongly agree (5). The questions included: (1) I participate in the discussion/advocacy of human rights issues using social media platforms; (2) I have created/initiated a written/video story concerning human rights issues using the social media; (3) I share/retweet/rebroadcast written/video stories concerning human rights violation using the social media; (4) I have condemned a case(s) of human rights violation in Nigeria using the social media; and, (5) I use the social media to commend advocates of human rights development in Nigeria.

Perception of social media effectiveness. Two items on a 5-point Likert scale were used to measure this variable. The questions were: (1) I feel a compulsion to act after seeing stories concerning human rights violation posted on the social media; (2) Social media are effective means of advocating human rights development issues. The likely responses ranged from Strongly disagree (1) to Strongly agree (5).

Ethical considerations. Before the commencement of actual data collection, the researchers sought the informed consent of the potential participants through an appropriate brief on the main objectives of the research. Only those who indicated willingness to participate in the study were included in the final sample and given a copy of the research questionnaire. The collected information was kept confidential.

Data analysis. The data were analyzed using mean $(\bar{X})$ and Standard Deviation (SD) with cutoff points set at 3.00 and 1.41 respectively. Thus, any item with a mean score of less than 3.00 was rejected, while mean scores greater than 3.00 were accepted (Nworgu, 2006). SPSS Version 23 was used to conduct bivariate analyses to determine the variables associated with the use of the social media for promoting human rights advocacy efforts in Nigeria. 


\section{Results}

The analysis was based on 909 copies of the questionnaire that were returned and found usable, representing $91 \%$ response rate. Based on the sociodemographic characteristics of the respondents, $40.8 \%$ of the participants were females compared to $59.2 \%$ who were males. On the basis of age grouping, $7.7 \%$ fell within the range of $16-20$ years old, $40.8 \%$ were between $21-34$ years old, $18.3 \%$ were aged $35-44$ years old, $13.4 \%$ were $45-54$ years old, $5.8 \%$ were aged 55-64 years old and the remaining 14\% were 65 years old and above. On the basis of highest educational attainment, $20 \%$ of the respondents have received elementary or secondary education, $67 \%$ had a Bachelor's degree or its equivalents, while the remaining $13 \%$ had postgraduate degrees. $63 \%$ of the respondents had some forms of active employment, while $37 \%$ were unemployed.

To reduce bias and determine the extent of representativeness of the sample, we compared the obtained sample results with the national population as recommended by previous studies (Balter \& Brunet, 2012). Although respondents with higher education were somewhat oversampled, the sociodemographic stratification of the study participants did not differ much from that of the general Nigerian online population. Compared to the Nigerian online social stratification, $67 \%$ of Nigerian netizens are males, $78 \%$ are between the ages of 19 and 35 years old, and at least $45 \%$ are students (Teragon Insight, 2013). In relation to the offline stratification, the national demographic spread shows that there are 1.04 males for every female in Nigeria and a significant proportion of the population is comprised by young people between the ages of 15 and 35 years old, with the median age being 19 years and three months (NBS, 2018; Teragon Insight, 2013).

The results presented in Table 1 show that the respondents are well exposed to human rights issues posted on the social media in the forms of videos and written stories, and they have acquired relevant knowledge on the issue as a result of their exposure. Based on the results, many of the respondents usually see videos/written stories concerning human rights violation posted on the social media, they have also acquired relevant knowledge on human rights issues through the social media. However, many of the respondents do not belong to human rights advocacy groups/chat rooms/pages on the social media and only few of them usually receive requests on the social media urging them to append their signatures to online petitions against cases of human rights violations in Nigeria. 
Table 1

\section{Exposure to human rights advocacy messages posted on the social media}

\begin{tabular}{|c|l|c|c|}
\hline \multicolumn{2}{|c|}{ ITEM } & Mean & SD \\
\hline $\mathbf{1}$ & $\begin{array}{l}\text { I do come across videos/written stories concerning } \\
\text { human rights violation posted on the social media }\end{array}$ & 4.12 & 1.04 \\
\hline $\mathbf{2}$ & $\begin{array}{l}\text { I have received requests on the social media urging me } \\
\text { to sign online petitions against human rights violation } \\
\text { in Nigeria }\end{array}$ & 2.83 & 1.54 \\
\hline $\mathbf{3}$ & $\begin{array}{l}\text { I am a member of human rights advocacy group/ } \\
\text { chat room/page on the social media }\end{array}$ & 2.45 & 1.38 \\
\hline $\mathbf{4}$ & $\begin{array}{l}\text { I have acquired much knowledge on human rights } \\
\text { issues through the social media }\end{array}$ & 4.15 & 1.10 \\
\hline
\end{tabular}

Data in Table 2 indicate that most of the respondents participate in human rights advocacy through discussions on social media platforms, sharing/ retweeting/rebroadcasting videos/written stories, lending their voices to condemn cases of human rights violation, and commending advocates of human rights. However, despite the respondents' wide participation in human rights advocacy efforts using the social media, majority of them seldom create/initiate written/video story concerning human rights issues using the online platforms.

Table 2

Ways of participation in human rights advocacy using the social media

\begin{tabular}{|c|l|c|c|}
\hline \multicolumn{2}{|c|}{ ITEM } & Mean & SD \\
\hline $\mathbf{1}$ & $\begin{array}{l}\text { I participate in the discussion/advocacy } \\
\text { of human rights issues using social media platforms }\end{array}$ & 4.16 & 0.83 \\
\hline $\mathbf{2}$ & $\begin{array}{l}\text { I have created/initiated a written/video story } \\
\text { concerning human rights issues using the social media }\end{array}$ & 2.58 & 1.12 \\
\hline $\mathbf{3}$ & $\begin{array}{l}\text { I share/retweet/rebroadcast written/ } \\
\text { video stories concerning human rights violation using } \\
\text { the social media }\end{array}$ & 3.19 & 1.04 \\
\hline $\mathbf{4}$ & $\begin{array}{l}\text { I have condemned a case(s) of human rights violation } \\
\text { in Nigeria using the social media }\end{array}$ & 3.95 & 1.14 \\
\hline $\mathbf{5}$ & $\begin{array}{l}\text { I use the social media to commend advocates } \\
\text { of human rights development in Nigeria }\end{array}$ & 4.21 & 0.63 \\
\hline
\end{tabular}

Table 3 shows that the respondents perceive the social media as potent tools for promoting human rights advocacy efforts in Nigeria; hence, they also feel compelled to act when exposed to such (human rights advocacy) issues on the social media. 
Table 3

Perception of the social media as effective tools for human rights advocacy

\begin{tabular}{|c|l|c|c|}
\hline \multicolumn{1}{|c|}{ ITEM } & Mean & SD \\
\hline $\mathbf{1}$ & $\begin{array}{l}\text { I feel a compulsion to act after seeing stories concerning } \\
\text { human rights violation posted on the social media }\end{array}$ & 3.98 & 1.08 \\
\hline $\mathbf{2}$ & $\begin{array}{l}\text { Social media are effective means of advocating human } \\
\text { rights development issues }\end{array}$ & 4.39 & 0.87 \\
\hline
\end{tabular}

We conducted a series of bivariate analyses to determine the various demographic and psychographic factors associated with the use of the social media for human rights advocacy efforts in Nigeria. Results of the Spearman's Rank correlation analysis presented in Table 4 show that gender, education, exposure to human rights issues on the social media and the perceived effectiveness of the social media are some of the factors that are significantly associated with public deployment of social media tools in human rights advocacy efforts. However, participation in human rights promotion activities was not significantly associated with respondents' age and employment status.

Table 4

\section{Correlation matrix between variables}

\begin{tabular}{|c|c|c|c|c|c|c|}
\hline Variables & $\mathbf{1}$ & $\mathbf{2}$ & $\mathbf{3}$ & $\mathbf{4}$ & $\mathbf{5}$ & $\mathbf{6}$ \\
\hline Gender & - & & & & & \\
\hline Age & .211 & - & & & & \\
\hline Education & .314 &. $.366^{*}$ & - & & & \\
\hline Employment status & $.232^{*}$ & $.428^{* *}$ & $.624^{* *}$ & - & & \\
\hline SM exposure & $.241^{*}$ & $.222^{*}$ & $.283^{*}$ & -.418 & - & \\
\hline Perception of SM & $.283^{* *}$ & .331 & $.454^{* *}$ & .235 & $.463^{* *}$ & - \\
\hline $\begin{array}{c}\text { Participation } \\
\text { in Human Rights Advocacy }\end{array}$ & $.528^{*}$ & .423 & $.674^{* *}$ & -.148 & $.421^{* *}$ & $.753^{* *}$ \\
\hline
\end{tabular}

Correlation is significant at $<0.01$ and $<0.05$ levels (2-tailed).

1 = Gender; 2 = Age; 3 = Education; 4 = Employment status;

5 = Social media exposure; 6 = Perception of Social Media

\section{Discussion}

The unprecedented popularity of the social media has opened greater opportunities for a wider section of the society to be actively engaged in human 
rights promotion efforts. Our study attempts to provide answers to how the social media encourage community-wide engagements in the advocacy for human rights protection and promotion in Nigeria, thereby shifting focus from the sole reliance on the mainstream media for human rights promotion activities. First, this research showed that many Nigerians are adequately exposed to issues of human rights violations and advocacy in the forms of videos and written stories. Essentially, this appreciable level of exposure was made possible through the various social media platforms; thus, corroborating previous studies (Fafoyin, 2011) which posit that social media tools are critical for promoting access to and utilization of key services that aid the fulfillment of human rights, particularly when they are appropriately deployed. From our results, majority of the respondents agreed that the social media have enabled them to acquire relevant knowledge on human rights issues, although only a few of them seem to have joined human rights groups on the various social media platforms. No doubt, knowledge and awareness are essential to the quest for social development, and the social media seem to have provided these essential elements to users in Nigeria, thereby equipping them for the task of human rights promotion and advocacy.

Observably, the appreciable level of awareness on human rights issues, made possible by the social media, has an analogous level of participation in human rights advocacy efforts. The findings indicated that the respondents use the social media to participate in human rights advocacy activities in different ways, including active involvement in human rights discussions and debates, denunciation of brazen acts of human rights infringement and commendation of individuals, groups and governments championing human rights development efforts in Nigeria. All these essentially constitute the roles of the mass media in human rights protection (Asemah et al., 2013). Specifically, a large majority of the respondents admitted to being actively involved in the sharing of stories on human rights issues via Facebook, retweeting such information on Twitter and rebroadcasting them on Whatsapp or similar social media platforms. This finding partly supports one of the core assumptions of the Media Systems Dependency Theory which posits that the availability of information resources can influence the cognitive, affective and evaluative domains of individuals and stimulate changes in the way they respond to societal trends (Wimmer \& Dominick, 2011).

However, a vast proportion of the respondents seldom utilize the social media to initiate/create fresh actions on human rights advocacy efforts, although they are actively involved in the sharing of videos and written stories that are related 
to human rights activism. This may not have been totally unexpected considering that the respondents were not core human rights activists and, as such, may not be vast enough in terms of knowledge to create new stories and initiate fresh actions on the promotion of human rights. Besides, previous research has also shown that while many social media users tend to frequently engage in general online activities like chatting and non-specific information search, certain online activities, such as content creation, are mainly undertaken by a few users of the Web 2.0 based platforms (Bennette \& Maton, 2010).

The study went further to determine the respondents' perception on the effectiveness of the social media as tools for promoting human rights advocacy efforts in Nigeria. According to our results, many of the respondents perceive the social media as potent and effective means of advocating the protection of human rights. Consistent with previous studies (Dunu \& Uzochukwu, 2015; Mwilima \& Matali, 2018; Zanzoun, 2017), many of the respondents agreed that they felt compelled to take necessary actions after seeing stories concerning human rights violation posted on the social media. This underscores the power of the social media in the mobilization of people and stimulation of social action against societal ills and institutional frailties. Such actions by the public would usually come in the forms of sharing, retweeting, rebroadcasting and reposting messages either to condemn human rights violation or praise efforts to deepen human rights protection in the country.

Finally, our results showed that certain demographic characteristics, such as gender, education, exposure to human rights issues on the social media and the perceived effectiveness of the social media are some of the factors that are significantly associated with the use of the social media for human rights promotion efforts. Nevertheless, respondents' age and employment status are not significantly associated with the use of the social media for human rights advocacy. This suggests that having higher education, being frequently exposed to human rights issues via the social media, and having a positive perception towards the effectiveness of the social media as potent tools for human rights advocacy might index people for the deployment of online platforms in the advancement of social development issues, such as human rights.

\section{Conclusion}

A principal target of the study was to fill the seeming gap in knowledge concerning how the social media promote community engagement in social development issues and index users in Nigeria for active involvement in human rights advocacy efforts. One of the practical implications of the present study is its affirmation of 
the Web 2.0 based technologies as potent tools for promoting social development issues, such as human rights advocacy. Through the various social media platforms, many people in Nigeria get exposed to human rights related information, and such considerable high level of exposure also tends to have a corollary effect of wider public participation in the discussion and spread of human rights related information, condemnation of human rights violation and commendation of efforts aimed at entrenching the culture of human rights protection in Nigeria.

Thus, conclusion could be drawn that the social media have engendered a community wide participation and engagement of people in efforts aimed at reducing incidences of human rights violation in Nigeria. Another important contribution of the study to practical knowledge is the identification of certain personal and psychographic characteristics like gender, education, exposure to and perception of the social media as some of the factors that are significantly associated with the deployment of online digital technologies for human rights advocacy purposes in Nigeria.

Hence, it is recommended that social media users in Nigeria should sustain their current tempo of involvement in the promotion of human rights issues so as to continually put such issues on the front burner and attract necessary actions from concerned stakeholders in the long run. Importantly, Nigerian netizens should strive for a greater measure of credibility in their deployment of the social media in human rights promotion efforts by avoiding the lure of making unsubstantiated or false claims to human rights breaches. Given the high level of exposure to digitally mediated human rights information, it is recommended that rights activists, groups and organizations should leverage the potentials of the social media to inform and educate members of the public on what constitutes citizens' fundamental rights and their breaches. It is recommended that government should monitor and pay salient attention to social media posts on human rights violations in order to take timely action to nip such abuses in the bud and prevent them from snowballing into national crises.

\section{References}

AGBOR, C. A. \& ASHABUA, D. A. (2018). Basic education curriculum in SouthSouth Nigeria: Challenges and opportunities of quality contents in French language learning. Global Journal of Education Research, 17. pp. 97-101. Available from: https://dx.doi.org/10.4314/gjedr.v17i2.1.

AKOJA, M. L. (2016). Audience participation and perception of media programmes: Implications for national development. Journal of Research and Development, 2(12), pp. 1-7. 
ASEMAH, E. S., EDEGOH, L. O., \& OGWO, C. (2013). Employing the mass media for the promotion of human rights in Nigeria. African Research Review, 7(1), pp. 47-60. Available from: http://dx.doi.org/10.4314/afrrev.v7i1.4.

ASEMAH, E. S. ET AL. (2017). Research methods and procedures in mass communication. Jos, Nigeria, Matkol Press.

Amnesty international Nigeria (2019). Nigeria: Human rights agenda. Available from: http://www.amnesty.org/en/documents/afr44/o431/2019/en

AUGER, G. A. (2013). Fostering democracy through social media: Evaluating diametrically opposed nonprofit advocacy organizations' use of Facebook, Twitter, and Youtube. Public Relations Review, 39, pp. 369-376. Available from: https:// doi.org/10.1016/j.pubrev.2013.07.013

BALTAR, F. \& BRUNET, I. (2012). Social research 2.0: Virtual snowball sampling method using Facebook. Internet Research, 22(1), pp. 57-74. Available from: https://doi.org/10.1108/10662241211199960

BENNETT, S. \& MATON, K. (2010). Beyond the 'digital natives' debate: Towards a more nuanced understanding of students' technology experiences. Journal of Computer Assisted Learning, 26(5), pp. 321-331. Available from: http://doi.org/ 10.1111/j.1365-2729.2010.00360.x

BASSLER, A. ET AL. (2008). Developing effective citizen engagement: A how-to guide for community leaders. Available from: http://www.rural.palegislature.us/ effective_citizen_engagement.pdf

CHOUDHURY, P. S. (2011). Media in development communication. Global Media Journal, 2(2), pp. 1-13. Available from: http://www.caluniv.ac.in/global-mediajournal/Winter\%20Issue\%20December\%202011\%20Commentaries/C-5\%20 Sen\%20Choudhury.pdf

DUNU, I. V. \& UZOCHUKWU, C. E. (2015). Social media: An effective tool for social mobilization in Nigeria. Journal of humanities and social science, 20(4), pp. 10-21. Available from: http://www.iosrjournals.org/iosr-jhss/pages/archive.html

EJIFOMA, R. (2016). Nigeria: Enugu recorded highest number of human rights violations in 2015. All Africa, $17^{\text {th }}$ January, 2016. Available from: http://www. allafrica.com/stories/201601182073

ERUBAMI, A. J. (2020). Public perception of social media contributions to political participation processes in Delta State, Nigeria. Acta Universitatis Danubius. Communicatio, 14(1), pp. 110-126. Available from: http://www.journals.univdanubius.ro/index.php/communication/article/view/6680

FAYEMI, K. (2012). Digital governance in Nigeria: Going beyond the hype - The Ekiti State digital media study. Journal of Communication, 1(2), pp. 23-58. 
FAYOYIN, A. (2011). Promoting children's rights through the new media: The Nigerian experience. Journal of Communication, 2(2), pp. 57-65. Available from: http://krepublishers.com/02-Journals/JC/JC-02-0-000-11-Web/JC-02-0-000-11Contents/JC-02-0-000-11-Contents.htm

Internet world stats (2020). Internet penetration in Africa 2020 - Q1-March. Available from: http://www.internetworldstats.com/stats1.htm

MCPHERSON, E. (2015). ICTS and human rights practice: A report prepared for the UN special rapporteur on extrajudicial, summary, or arbitrary executions. Available from: https://www.researchgate.net/publication/330728901_ICTs_and_ Human_Rights_Practice_A_Report_Prepared_for_the_UN_Special_Rapporteur_ on_Extrajudicial_Summary_or_Arbitrary_Executions

MCPHERSON, E. (2017). Social media and human rights advocacy. In: H. Tumber \& S. Waisbord, The Routledge companion to media and human rights, London, UK, Routledge, pp. 279-288. Available from: https://www.academia. edu/34691336/Social_Media_and_Human_Rights_Advocacy

MWILIMA, F. J. \& MATALI, M. (2018). Social media as an effective communication tool for youth engagement on social political issues: A case study of the affirmative repositioning movement in Namibia. The Journal World of Media: Journal of Russian Media and Journalism Studies, 1, pp. 49-58. DOI: 10.30547/worldofmedia.1.2018.4. Available from: http://www.worldofmedia.ru/ volumes/2018/2018_Issue_1/

NAH, S. \& SAXTON, G. D. (2013). Modeling the adoption and use of social media by nonprofit organizations. New Media \& Society, 15(2), pp. 294-313. Available from: http://doi.org/10.1177/1461444812452411

Nigeria. National bureau of statistics (2018). Demographic statistics bulletin. Available from: http://www.nigerianstat.gov.ng/download/775

Nigeria. National bureau of statistics (2020). 2019 poverty and inequality in Nigeria: Executive summary. Abuja, Nigeria: NBS. Available from: https:// nigerianstat.gov.ng/download/1092

NICHOLSON, B, NUGROHO, Y., \& RANGASWAMY, N (2016). Social media for development: Outlining debates, theory and praxis. Information Technology for Development, 22(3), pp. 357-363. Available from: http://dx.doi.org/10.1080/02 681102.2016.1192906

NWORGU, B. G. (2006). Educational research: Basic issues and methods. Enugu, Nigeria, University Trust Publishers.

NZARGA, F. D. (2014). An analysis of human rights violation by the Nigerian security services. Journal of Law, Policy and Globalization, 30(1), pp. 1-8. Available from: https://www.iiste.org/Journals/index.php/JLPG/article/view/16329/16849 
OJI, M. \& ERUBAMI, A. J. (2020). Discourse on social media use and reading culture of Nigerian youths. Academic Journal of Interdisciplinary Studies, 9(6), pp. 105-13. Available from: https://doi.org/10.36941/ajis-2020-0115

OKEKE, E. O. (2014). Role of the mass media in the advancement of human rights. Journal of Social and Management Sciences, 9(2), pp. 24-33.

PATE, U. A. (2011). The press, social responsibility and the coverage of human rights issues in Nigeria during the Abacha's regime. In: L. Oso \& U. A. Pate, Mass media and society in Nigeria, Ibadan, Nigeria, Malthouse Press.

RAHMAN, M. M. (2016). Using social media to promote human rights. Daily Sun, 21st March, 2016. Available from: http://www.daily-sun.com/arcprint/ details/122250/Using-social-media-to-promote-human-rights/2016-03-21

RIFFE, D., LACY, S., \& VAROUHASKIS (2008). Media system dependency theory and using the internet for in-depth, specialization information. The Web Journal of Mass Communication Research. Available from: http:///www.wjmcr. info/2008/01/01/media-system-dependency-theory-and-using-the-internet-forin-depth-specialized-information

SOOLA, E. O. (2003). Development communication: The past, the present and the future. In: E. Soola, Communication for development purpose, Ibadan, Nigeria, Kraft Books.

Teragon insights (2013). State of digital media in Nigeria. Lagos, Nigeria: Teragon Insights Limited. Available from: https://nairametrics.com/wp-content/ uploads/2013/05/Nigeria-State-of-Digital-Media.pdf

THRALL, A. T., STECULA, D., \& SWEET, D. (2014). May we have your attention please? Human-rights NGOS and the problem of global communication. The International Journal of Press/Politics, 19(2), pp. 135-159. Available from: http:// dx.doi.org/10.1177/1940161213519132

UNICEF. Nigeria: Child Protection. Available from: https://www.unicef.org/ nigeria/child-protection

United Nations. Transforming our world: The 2030 agenda for sustainable development. Available from: https://sustainabledevelopment.un.org/post2015/ transformingourworld

UWAKWE, O. (2012). Development communication: Philosophy and practice. Awka, Nigeria, Amaka Dreams.

WIMMER, R. D. \& DOMINICK, J. R. (2011). Mass media research: An introduction. Boston, USA, Cengage Learning.

ZANZOUN, M. (2017). The use of social media in promoting human rights among speakers of English in Morocco: The case of Facebook. International Journal of Education and Research, 5(9), pp. 169-184. Available from: https://www.ijern.com/ september-2017.php 